\title{
A Nursing Study Abroad Experience in the Blue Zone of Sardinia, Italy: A Case Study of the Program and Development
}

\author{
Jessica Naber", Amy Hale \\ School of Nursing and Health Professions, Murray State University, 102 Curris Center, Murray, KY 42071, USA
}

\begin{abstract}
Article Details
Article Type: Review Article

Received date: $26^{\text {th }}$ August, 2019

Accepted date: $14^{\text {th }}$ September, 2019

Published date: $16^{\text {th }}$ September, 2019

"Corresponding Author: Jessica Naber, Associate Professor, School of Nursing and Health Professions, Murray State University, 102 Curris Center, Murray, KY 42071, USA. E-mail: jnaber@murraystate.edu

Citation: Naber J, Hale A (2019) A Nursing Study Abroad Experience in the Blue Zone of Sardinia, Italy: A Case Study of the Program and Development. J Comp Nurs Res Care 4: 146. doi: https://doi.org/10.33790/jenrc1100146.

Copyright: (C2019, This is an open-access article distributed under the terms of the Creative Commons Attribution License 4.0, which permits unrestricted use, distribution, and reproduction in any medium, provided the original author and source are credited.
\end{abstract}

\begin{abstract}
Each year, more than 300,000 American students have an international experience to earn academic credit on a variety of programs ranging from two weeks to a full academic year. Education Abroad (EA) enables students to "experience new perspectives, learn how to navigate different cultures, work with diverse peers, and communicate in other languages" [1]. In nursing, studying abroad has been shown to help with cultural awareness, personal growth, cultural immersion, and networking. EA opportunities help nursing students to gain "diverse cultural perspectives, as well as global competence" [2] in a world where they will be providing care for an increasingly diverse population.
\end{abstract}

At a mid-size university in the American South, an associate professor in nursing who has previous EA experience, became interested in a health-related concept known as the Blue Zones, described below. She realized that this particular research area of interest could be applied to an opportunity for a health-related study abroad program for nursing students and other college students interested in the concept. In this article, the authors will describe the concept of Blue Zones, how an EA program focusing on the concept was developed, what was involved in the course connected with the program, and details of the experience.

\section{Blue Zones}

There are five areas of the world, known as Blue Zones, where the largest numbers of centenarians, or people living greater than 100 years, reside. (The current average life expectancy of people in the United States is 78.9 years) [3]. The regions of Sardinia, Italy; Loma Linda, California; Okinawa, Japan; Nicoya, Costa Rica; and Ikaria, Greece were studied in great detail by Dan Beuttner and National Geographic, following up on research by Poulain et al. [4], to determine why and how people living in these zones were able to live longer and healthier than those in other areas of the world. Nine similarities, dubbed the Power 9, were found among the Blue Zones including moving naturally, knowing one's purpose, down shifting one's life, surrounding oneself with a tribe of people, belonging to a religious group, putting one's family first, having a glass of red wine at least once per day, including larger portions of vegetables, and eating only until 80 percent full [5].

\section{Education Abroad Program Development}

In 2014, a nursing professor became interested in the concept of the Blue Zones after reading about Buettner's research online. The concept was intriguing to someone involved in healthcare because in the Blue Zone areas, people were living longer than in the United States at an astounding rate, and more importantly, they were living healthier. For example, in Ikaria, Greece, people on average live eight years longer than Americans and have 20\% less cancer, half the rate of heart disease, and no dementia. In Loma Linda, California, residents outlive other Americans by a decade. In Sardinia, Italy, there are more male centenarians than anywhere on the globe. In Okinawa, Japan, the world's longest-living females reside. And in Nicoya, Costa Rica, people are twice as likely as Americans to live to 90 years old [5]. When someone in healthcare learns about these statistics, many questions naturally arise: What are they doing differently? How do they do it? Could these lifestyles, behaviors, and routines be modelled by people in the U.S.?

Because of a desire for knowledge acquisition about all things related to living healthier, the professor decided that in addition to reading about these places, it would be valuable to visit these locations, observe and talk to the people, and learn about living healthier from some true experts. Additionally, she believed it would be of great value to take nursing students along so they could bring back the knowledge to their communities and patients. Upon further reflection, she realized that students other than just nursing could really benefit from this knowledge as well. She reached out to EA coordinators at her university and discussed the idea of taking students to these sites for true immersion and experiential learning.

EA coordinators were supportive of this experience and felt it had merit and value. In 2015, the professor completed the application process used by the university. Included in the application was a description of the program to the selected location of Sardinia, Italy, and a syllabus outlining course objectives and assignments (see next section). The program was approved for the Summer of 2017 based on rigor, recruitability, and educational value. She and the EA staff contacted education abroad providers and found an organization that would be willing and able to assist with the requested program and itinerary.

The next year consisted of recruitment efforts by the professor, other colleagues in her department, colleagues across campus, and 
EA representatives. She spoke to classes of students in each semester of the nursing program, including pre-nursing students but excluding senior students who would graduate prior to the travel date, and had a great deal of interest. Included in these visits was an explanation of what Blue Zones are, how the concepts are applicable for nurses and their patients, and why visiting the Blue Zone of Sardinia, Italy would be of value to nursing students. Details of the itinerary were shared as well as cost and course credit. She was able to recruit 17 nursing students, and it was decided among the professor, the EA coordinators, and the provider that that would be an adequate maximum number of students to take to Sardinia. Due to achieving this set capacity by recruiting in nursing, the professor was unable to recruit in other departments and disciplines, although there was interest from students in a variety of disciplines.

\section{The Program and Course}

Much thought, time, research, and reflection must go in to the development of an EA program and course. It is vital that courses abroad maintain an appropriate level of rigor, not only to uphold the reputation of EA, but also to maximize the learning experience for students while abroad [6]. When developing this particular program, the faculty member determined that the ultimate goals were for the students to learn about Blue Zone and bring the concepts back to families, peers, community members, and patients and also to engage in a research component. Below you will find details about the specifics of the program and course.

\section{Course Description}

For the course offered in conjunction with this travel experience, the focus was on exploring Italy's Blue Zone in Sardinia with attention to sociocultural practices such as diet, activity, exercise, religion, and agriculture. The course also had a component where students investigated unique healthcare techniques and practices, including alternative treatments and therapies, university education, hospital structure, and healthcare systems throughout Italy. Because the group would be travelling to Italy, the professor planned stops in Florence and Rome on the way to the island of Sardinia.

\section{Course Objectives}

Upon completion of this course, the objectives were for the student to obtain an understanding of the current structure of the Italian healthcare system, explore sociocultural contributions to health and illness in the U.S. and Italy, compare health practices in the U.S. and Italy, and understand the Blue Zone concept as a research project. When taking nursing students abroad, it is always important to expose them to healthcare practices, procedures, and systems and allow them to compare the foreign practices to healthcare in the U.S. Additionally, the goal was for the students to understand what Blue Zones are, how residents live and behave, and how this knowledge can be disseminated.

\section{Grading Procedures}

In any EA course, as part of maintaining rigor and following course guidelines, grades must be assigned. For this particular course, the breakdown was as follows: Class Participation and Discussion (20\%); International Reflective Journal (20\%); Blue Zone presentation (30\%); Class Presentation Murray (15\%); and Class Presentation Italy (15\%). Descriptions of these components are detailed below.

\section{Course Activities}

For this course, credit was given for a Spring 2017 class, based on University policy. It was considered a second-half semester course, so the professor met with the students weekly during the second half of the spring semester. In these class meetings, they discussed the plan for the course, analyzed Dan Buettner's book The Blue Zones: Nine Lessons for Living Longer from People Who've Lived the Longest (2012), discussed interactions with Italian citizens, determined goals for Blue Zones research, and conducted and viewed presentations.
Students were required to choose three presentation topics from lists provided. Some of the terms were non-nursing related locations that they would be visiting (such as the Pantheon or the Duomo), and some were nursing-related (such as Italian nursing education or thermal baths). These presentations could be done individually or in pairs. A maximum of seven minutes was suggested, a rubric was provided, and creativity was encouraged. For the nursing-related presentation, students were required to include information about similarities and differences between US and Italy. For non-nursing locations, they were required to include any connections to health care and information classmates might need to be aware of. At one class meeting, they each presented two topics, and in Italy, they presented the other.

At the class meeting prior to departure, students had to do Blue Zone presentations, with a partner or individually. It was recommended that they attend any Blue Zone speaking events in the community prior to this meeting, and there was one presentation in a nearby community that they could attend. They had to discuss what they had learned about Blue Zones (based on websites, speaking events, books, literature, etc.), what they hoped to learn about Blue Zones, and what they hoped to bring back to the community with regards to the Blue Zones. They were to include several specific things they would like to implement both individually and in the community.

Students were required to maintain a reflective journal throughout their experience that included the following: at least 2-3 pages per day, showing evidence of comparison of US and Italian culture, with emphasis on health care similarities and differences and Blue Zone ideals; a 2-3 page journal entry about specific encounter/conversation with an Italian citizen about health; a 3-4 page journal entry with an overall analysis of the visited Blue Zone. This journal was to show evidence of a depth of analysis of the culture as well as to document this EA experience for later reflection.

\section{Schedule of Activities}

The professor worked closely with the EA office and the provider to develop a one-of-a-kind, unique experience for the students. The itinerary was revised and edited throughout the planning process to best fit the needs of the students and to meet the objectives of the course. The final itinerary was as follows:

\section{Day $1 / 2$}

- Flight and arrive in $\cdot$ Religion and food are two Florence at hotel points within the Power9 that - Walking tour of the students studied while Florence (the in Italy. By touring Florence Duomo, one of Italy's with a local guide, the largest churches, the students were able to better adjacent baptistery, understand how important the Palazzo Vecchio religion was in this region. and Ponte Vecchio) - The dinner was held at

- Welcome dinner as a a local restaurant which group provided the students with an authentic four course meal typical of Florence. Food is a major aspect of the Power9 including the types of foods eaten, the portions of specific foods, and the inclusion of relaxation and family/friends in the setting is something that is important as well.

Table to be Cont...... 


\section{Day 3}

- Group visit in - Founded in the year 1288, the morning to Santa Maria Nuova hospital Zoological Museum La Specola

- Group visit in the afternoon to Santa Maria Nuova hospital is the oldest working hospital in Florence. Information was shared regarding some differences in healthcare in Italy versus the United States in terms of cost and availability for tests and procedures.

Day 4

- Travel by bus to - At the thermal bath, students thermal bath in learned about the importance Tuscany to learn about thermal therapy

- Bus ride to Rome and arrive at hotel

- Guided walking tour of Rome (Piazza Barberini, Piazza majestic staircase, Fontanta di Trevi, Pantheon, and Piazza Navona)

- Group dinner of the minerals which are found in the water and their positive effects on the body, both internally and externally.

The guided tour provided students with the ability to understand further the layout of the city. As with Florence, foot traffic in this area was heavy which aligns with the Power9 in moving more naturally. di Spagna with its

- The dinner portion of the day was provided by a local restaurant. The meal consisted of three courses including an appetizer, main pasta course, and a desert. The meal is one typical of Roman eateries.

Day 5

- Visit to home health nursing service

- Free afternoon to explore Rome and visit Borghese Gallery

Students had the ability to listen to a presentation and interact with the speaker at the home health nursing service to understand how similar/different these types of services were from those in the United States.

- The purpose of free time was to allow students to integrate themselves within the community and to further learn about the people of the area.

\section{Day 6}

- Visit to International Medical Clinic and Surgical Clinic

- Afternoon visit to diagnostic center
Students listened to a presentation at the International Medical Clinic that was provided by a physician who discussed how his private practice worked which included some similarities/differences.

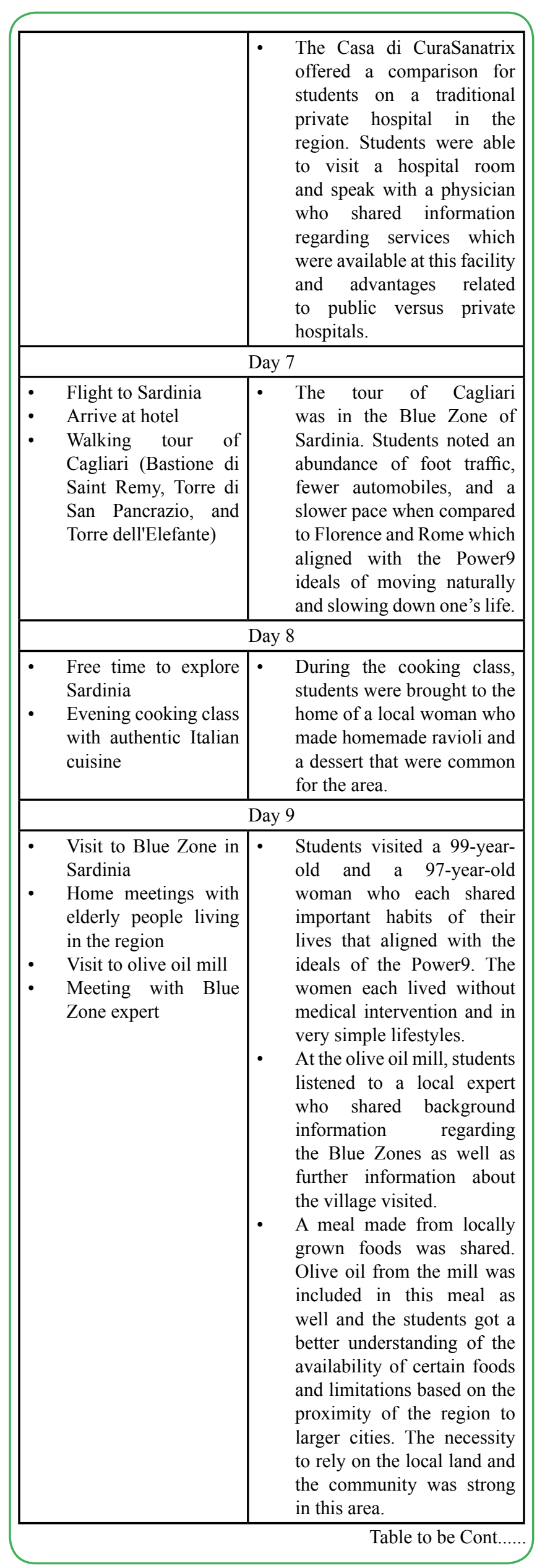




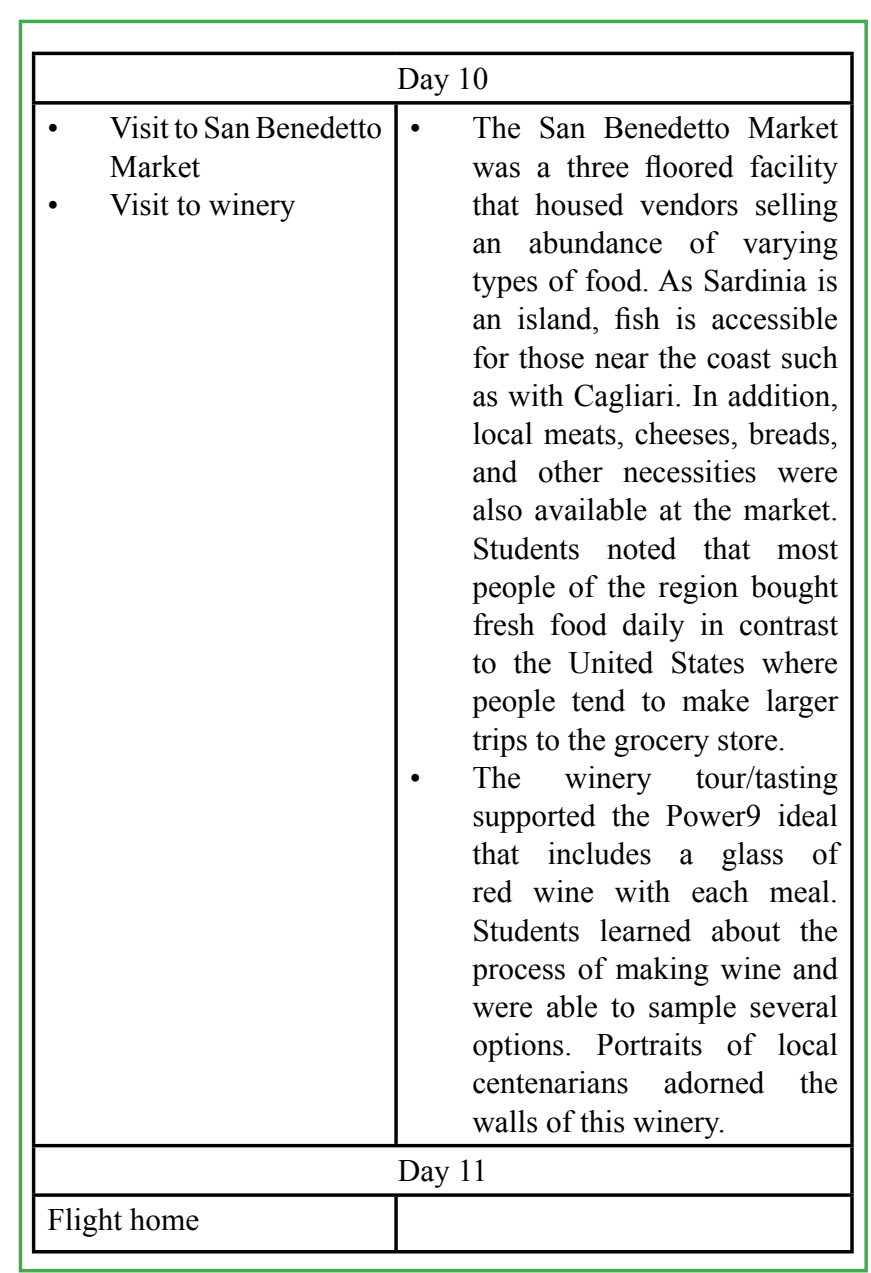

\section{The Experience}

In May 2017, the group of 17 nursing students from a mid-size university in the American South and their professor travelled to Florence, Rome, and the Blue Zone in Sardinia, Italy for a unique education abroad experience. In Florence, Rome, and Sardinia, the provider had an Italian guide to meet the group, help the group navigate to the locations, and be available for any questions or concerns. Each day, the group had breakfast at the hotel and then went on the various excursions listed above. Students kept their journals throughout the experience, and they made an effort to converse with locals and engage in learning about nursing and healthcare. They also presented on their selected topics at the appropriate times. For example, if a student chose to present on Italian Cuisine, she presented her information as the group walked to dinner. Or if someone chose to present on olive oil, he provided information as the group rode the bus to the olive oil mill.

One major goal of this program was to better understand the culture through immersion as well as via interaction with experts and local residents. Students were able to compare the healthcare system and facilities in Italy to healthcare and facilities in the U.S. They were able to explore sociocultural contributions to health and illness by talking with nurses and residents in the community. They compared health practices in the U.S. and Italy in their journals and conversations. They were also able to understand what a Blue Zone is and how it is different from cities in the U.S. as well as Rome and Florence. They were able to apply the Power 9 concepts to their thinking process in each place they visited, particularly in the Blue Zone of Sardinia. The information gained can be useful to help increase lifespan and well-being of people with whom these nursing students interact in the future.

Due to university policy, grades for the course were due quickly upon return. For this reason, no post-program requirement could be included. However, students were asked if they voluntarily wanted to continue working on Blue Zone research upon their return. Half of the students engaged in work with the professor after their return from Italy. Some opportunities included website development and updating, Facebook page development and updating, presentations at the local, regional, and international level, and manuscript development.

\section{Implications and Recommendations}

Research describing the value of EA is abundant [2,7]. This particular program was of great value to nursing students, the professor, the university, the community, and many patients that those future nurses will interact with. (For more detail about personal student experiences, please see the article in-press by Naber, 2019.)

One specific component of this EA experience that makes it unique is sustainability. Since there are five documented Blue Zones, the plan is for the professor and her colleagues to apply and recruit students for programs that will travel to each of the other locations over the next several years. Additionally, students are still working with the professor on ideas for presentations and implementation of Blue Zone ideals into communities and with patients.

\section{Conclusion}

EA is a valuable experience for students in any discipline. Tailoring programs for students in a particular area can be done with collaboration among the university EA representatives, faculty members, and potentially providers, if desired. It is important to find a theme or focus for the EA program that is of interest to the faculty person and will be interesting and of value to potential students. Additionally, the course connected with the program needs to be rigorous and engaging while accomplishing the set objectives. If the program can also focus on something with a potential for future engagement, or even research opportunities, that can be of great benefit to students as well.

Conflict of interest: The authors declare no conflict of interest.

\section{References}

1. United States Department of State. (2019) Why study abroad?

2. Mailloux CG (2017) Benefits of study abroad in nursing. J Nurs Patient Care 2.

3. World Population Review (2019) Life expectancy by country.

4. Poulain M, Pes G, Grasland C, Carru C, Ferrucci L, et al. (2004) Identification of a geographic area characterized byextreme longevity in the Sardinia island. Exp Gerontolo 39: 1423-29.

5. Buettner D (2012) The Blue Zones: Nine lessons for living longer from the people who've lived the longest. National Geographic Society: Washington, D.C.

6. University of Nicosia (2019) Standards of good practice for education abroad.

7. International Student (2019) Ten benefits to studying abroad. 